\title{
ANÁLISE DE RUÍDOS EM METRÓPOLES BRASILEIRAS: OBSERVAÇÕES EM CAMPO NA ZONA NORTE CARIOCA
}

\author{
Bruno Borges Mamede ${ }^{1}$ \\ Lucas Devides Moreno ${ }^{2}$ \\ Fernando Augusto Noronha de Castro Pinto ${ }^{3}$
}

\section{RESUMO}

Este estudo possui como objetivo a observação do comportamento dos níveis de pressão sonora em uma determinada área da Zona Norte da cidade do Rio de Janeiro, a partir dos conceitos de Engenharia Acústica. No caso de extrapolação dos limites legais estabelecidos quais medidas podem ser adotadas para mitigar o problema, tal qual uma reflexão a cerca de normatização destes. Entretanto, além da apresentação e discussão dos resultados bem como possíveis medidas mitigadoras, o principal objetivo aqui está no impacto dos níveis de ruído no cotidiano urbano a partir de sua disseminação (mensurável) no espaço das cidades e as possíveis formas de compatibilização destes para implemento da qualidade de vida local.

Palavras-Chave: Engenharia Acústica, Engenharia Urbana, Geografia Urbana, Geografia dos Transportes.

\section{ANALYSIS NOISE IN BRAZILIAN METROPOLISES: NOTES ON FIELD IN NORTH ZONE CARIOCA}

\footnotetext{
${ }^{1}$ Comunicador Social (PUC-Rio) e Geógrafo (UERJ), Aluno de Mestrado em PEU/POLI/UFRJ e de Especialização em IPPUR/UFRJ, bruno.mamede@poli.ufrj.br.

2 Engenheiro Civil (Mackenzie-SP), Aluno de Mestrado em PEU/POLI/UFRJ, lucas.moreno@poli.ufrj.br.

${ }^{3}$ Doutor em Engenharia (TUHH/Alemanha), Professor em PEU/POLI/UFRJ, fcpinto@ufr..br.
} 


\section{ABSTRACT}

This study's objective is to observe the conduct of sound pressure levels in a determinate area of Rio de Janeiro's North Zone, based in the Acoustics Engineering's concepts. In the case of legal limits' extrapolation which measures could be adopted to mitigate the problem, such as a reflection about the normalization of those ones. However, beyond presentation, discussion of the results and mitigate measures, the main goal here is in the impact of noise levels in the urban daily activities and the possible forms of compatibility for local life quality implement.

Keywords: Acoustics Engineering, Urban Engineering, Urban Geography, Transportation Geography.

\section{RUIDO EN ANÁLISIS METRÓPOLIS BRASILEÑAS: NOTAS EN CAMPO EN ZONA NORTE CARIOCA}

\section{RESUMÉN}

El objetivo de esta investigación es la observación del comportamiento de los niveles de presión sonora en un área determinada de la Zona Norte de la ciudad del Río de Janeiro, de acuerdo con los conceptos de Ingeniería Acústica. En el tocante a la extrapolación de los límites legales cuales medidas se pueden ser hechas para la mitigación de la problemática, así como una reflexión acerca de los propios parámetros de normalización de esas. Para tanto, además de la presentación, discusión de los resultados y maneras de mitigar los problemas, la meta principal de este estudio está en el impacto que los niveles de sonido afectan las actividades urbanas diarias frente las posibles formas de compatibilización para implemento a la calidad de vida local.

Palabras-Clave: Ingeniera Acústica, Ingeniería Urbana, Geografía Urbana, Geografía de Transportes.

\section{INTRODUÇÃO: PROPOSTA E OBJETIVO}

Conforme mencionado, este trabalho propõe-se a realizar a medição dos níveis de pressão sonora em uma determinada área da cidade do Rio de Janeiro e, a partir destes resultados, realizar o confronto perante a normatização legal dada 
pela Associação Brasileira de Normas Técnicas. Após isto, será realizada uma discussão tanto a cerca destes limites legais e, ao fim, possíveis medidas para minimizar o impacto dos altos níveis de ruído podem ser sugeridos em locais necessários.

Para realizar estas análises, foi utilizado um sonômetro profissional calibrado o qual aferiu a pressão sonora em dois pontos do bairro de Jardim Guanabara, Ilha do Governador, Zona Norte da Cidade do Rio de Janeiro. No próximo item deste escrito a descrição e caracterização dos pontos de aferição serão descritos com maior nível de detalhes. Por enquanto, faz-se importante mencionar que ambos os locais estão próximos à área comercial da Ilha do Governador prevalecendo o uso misto do solo (residencial e comercial).

A justificativa para este trabalho encontra-se no fato de que o estudo de ruídos de uma determinada zona urbana é relevante para as autoridades locais e regionais (dependendo da importância da área em questão), pois a partir dos questionamentos iniciais sobre os níveis de produção sonora de determinado empreendimento é possível determinar em qual local do espaço é mais pertinente a sua instalação. No tocante a este estudo, a análise de ruídos na área especificada está condicionada aos resultados obtidos, principalmente, pela proximidades dos eixos de circulação e o uso não homogêneo do solo, tal qual mencionado no parágrafo anterior. Deve-se considerar também que a área em questão, de acordo com Corrêa (2006) e IPP (2013), este bairro possui urbanização consolidada há muitas décadas e a transformação total da paisagem, mesmo que em prol de melhorias, deve atender a certos critérios.

A metodologia está pautada na aferição com sonômetro marca Bruel \& Kjaer modelo 2260 fornecido pela Universidade Federal do Rio de Janeiro (UFRJ) e sua última calibração data de 30/06/2011. Foram realizadas aferições em 04 ciclos de 01 minuto, sendo o parelho colocado a uma altura de 1,5 metro do solo e uma distância de 3,0 metros de fontes emissoras/refletoras de ruídos. Ressalta-se que em ambos os pontos foram utilizados os parâmetros mencionados. Para confronto com a normatização legal utilizou-se a NBR 10.151/2000 fornecida por ABNT 
(2000). A revisão bibliográfica está pautada basicamente nos impactos da poluição sonora no ambiente urbano, envolvendo assim teóricos das áreas de Geografia e Engenharias (Acústica, Transportes e Urbana), principalmente.

Após o apanhado teórico, técnico e legal pretende-se debater os resultados frente a questão da poluição sonora gerada pela circulação de veículos automotores em zonas urbanas de médio porte com franca expansão, como é o caso estudado. De acordo com Bezerra (1993) esta norma está em conformidade com os padrões estabelecidos pela Associação Mercosul de Normalização (AMN), do qual participam os institutos de normalização de cada país membro.

A exposição humana a altos níveis de ruído ocasiona respostas involuntárias e inconscientes do organismo e esse estímulo, bem como alterações na saúde humana especialmente na pressão sanguínea e visão. De acordo com Fernandes (2002), além das alterações biológicas, também são percebidas alterações bioquímicas no organismo. Desta maneira, o custo para tratamento destas enfermidades é contínuo e elevado, o que sobrecarrega o erário público bem como a rede de saúde local. Desde já, corrobora-se com o autor mencionado em sua afirmativa de que o controle de efeitos colaterais decorrentes de poluição sonora são extremamente necessários e menos custosos, tanto em valores financeiros como tratamentos de saúde, do que seus desdobramentos posteriores. Não apenas o custo está envolvido neste ponto, mas principalmente, a qualidade de vida da população local.

\section{ZONA NORTE CARIOCA E ILHA DO GOVERNADOR: CARACTERIZAÇÃO URBANA}

De acordo com IBGE (2000) e IPP (2013), o bairro de Jardim Guanabara está localizado na Itha do Governador, Zona Norte da cidade do Rio de Janeiro (RJ). Respectivamente, a população do bairro é de 32.213 habitantes e da ilha em sua totalidade de 211.018 habitantes. Ou seja, a população do Jardim Guanabara 
corresponde a $15,26 \%$ do total da ilha. Ainda, de acordo com os mesmos institutos, o bairro e da ilha representam, respectivamente, $0,05 \%$ e $3,28 \%$ dos 6.429 .923 habitantes de toda a capital fluminense.

Deve-se considerar que, em conjunto ao Jardim Carioca (bairro vizinho), este é o principal centro comercial de toda Ilha do Governador, com a oferta de serviços médico-hospitalares, bancários, educacionais e outros. Também é neste bairro onde circulam todas as linhas de chegada e saída as diversas regiões da llha com a porção continental da cidade do Rio de Janeiro e a llha do Fundão (onde está localizado o campus principal da UFRJ). Sendo assim, utilizando a classificação de Ferraz (2004) é o principal nódulo conector da região, além de compor um centro comercial expressivo e bem representativo da Zona Norte carioca.

Faz-se necessário comentar que esta zona carioca é extremamente heterogênea, possuindo bairros com áreas residenciais, comerciais e industriais, além do principal aeroporto do estado do Rio de Janeiro (Aeroporto Internacional Maestro Tom Jobim - Galeão, o qual está no bairro vizinho homônimo), comércio bem diversificado e vias de circulação que conectam a cidade ao restante do estado e do país, a exemplo da BR-116 Sul RJ (Via Dutra) que interliga a cidade do Rio de Janeiro a Baixada Fluminense, Sul Fluminense e o estado de São Paulo e a BR040, que interliga a capital fluminense à Duque de Caxias, Região Serrana e o estado de Minas Gerais. Os diferentes níveis de renda da população no espaço desta zona é um aspecto marcante na estratificação social dos distintos bairros. Desta maneira, logo após a região conhecida por Grande Tijuca (próxima ao Centro e Zona Sul da cidade), a llha do Governador compõe o núcleo com bairros de maior renda per capita da Zona Norte carioca.

Comentando um pouco sobre os locais analisados, foram escolhidos dois pontos próximos (distância linear inferior a 100 metros), mas com características bem distintas entre eles. O primeiro está localizado nas proximidades da Praça do Chafariz, ao fim da Estrada do Galeão e na confluência com a Avenida República Árabe da Síria, área de predominantemente comercial com edifícios de até 10 pavimentos. Neste ponto, está a divisão do tráfico entre as porções Sudeste, 
Centro-Leste e Nordeste da Ilha do Governador, sendo possível perceber o tráfego carregado ao longo de todo o dia, certamente, agravado nos horários de pico. Segundo Setti (2011) pode ser descrita como via arterial principal, não apenas do bairro, mas de toda a llha do Governador. Observam-se na via veículos desde motocicletas a caminhões de médio porte. A pavimentação da via é composta por capa betuminosa flexível e as calçadas modeladas em concreto. $O$ segundo ponto está situado na confluência das ruas Advogado Aylton Vasconsellos e Antônio Nascimento, sendo observada a predominância do uso residencial com a presença de edifícios pequenos com o limite máximo de 05 pavimentos. Observam-se também algumas casas de grande porte (até 03 pavimentos) em menor quantidade. As características de calçadas e pavimentação da via, aparentemente, seguem os mesmos padrões dos pontos já mencionados.

\section{AFERIÇÃO EM CAMPO E DISCUSSÃO DOS RESULTADOS}


Resultados Ponto A

\begin{tabular}{|l|c|c|c|c|}
\hline Mediçoes & Laq & Lmin & Lmax & Laeq \\
\hline Med 1 & 77,2 & 65,2 & 90,1 & 75,9 \\
\hline Med 2 & 71,4 & 65,2 & 90,1 & 75,6 \\
\hline Med 3 & 75,6 & 65,2 & 90,1 & 75,3 \\
\hline Med 4 & 74,2 & 65,2 & 90,1 & 75,4 \\
\hline
\end{tabular}

Resultados Ponto B

\begin{tabular}{|l|c|c|c|c|}
\hline Mediçōes & Laq & Lmin & Lmax & Laeq \\
\hline Med 1 & 58,9 & 51,0 & 68,3 & 58,1 \\
\hline Med 2 & 66,5 & 51,0 & 69,3 & 59,1 \\
\hline Med 3 & 64,5 & 50,3 & 69,3 & 58,6 \\
\hline Med 4 & 55,0 & 50,3 & 73,1 & 59,2 \\
\hline
\end{tabular}

Fonte: Próprios Autores (2013).

Após a estruturação do artigo, apresentação de dados do bairro e caracterização dos locais de medição, faz-se importante mencionar algumas informações importantes antes da apresentação dos resultados. Retomando, a análise foi realizada com um sonômetro digital devidamente calibrado fornecido pela UFRJ. O operador do aparelho foi o Prof. Dr. Fernando Augusto Pinto, responsável pela organização do campo e escolha dos pontos de medição, bem como todos os detalhes técnicos pertinentes a esta atividade. A medição foi realizada no dia 04 de dezembro de 2013, no período da manhã entre 11 e 12 horas. Isto posto, os resultados da aferição estão descritos nas tabelas da Figura 01 - Resultados de Aferição em Campo. Outro dado importante a mencionar é que a elaboração desta tabela foi realizada a partir das anotações em campo dos próprio autores.

Na Figura 02 - Limites ABNT para Emissão de Ruídos (em dB(A)) / NBR 10.151/2000, observam-se os limites estabelecidos para a emissão de ruídos de acordo com o tipo de uso do solo. Castro (2013) ressalta que, para a análise do 
valor aferido e comparação com os limites estabelecidos na NBR 10.151/2000, esta determina que seja obtida o valor inteiro das médias aritméticas percebidas em campo. Desta maneira, o valor integral unitário (obtido a partir das médias mencionadas) das medições nos pontos $A$ e $B$ são, respectivamente, $75 \mathrm{~dB}(\mathrm{~A})$ e 59 $\mathrm{dB}(\mathrm{A})$.

Ao aferir os níveis de pressão sonora, alguns princípios da Engenharia Acústica devem ser considerados. Primeiramente, de acordo com Möser (2009), faz necessário enquadrar o objeto de estudo de acordo com a especificidade do setor. Dentre as 13 áreas de estudo deste campo científico, identificou-se que, diretamente, o estudo encontra-se inserido mediante a Acústica Arquitetônica (ou de Edificações), Acústica do Ambiente, Controle de Ruídos, Dinâmica de Vibrações e Psicoacústica.

Retomando as afirmações de Fernandez (2002), os efeitos da poluição sonora difusa no ambiente da cidade provocam reações negativas e diversas nos saúde física e mental dos seres humanos, causando inaptidão para atividades produtivas, por exemplo. Assim, apenas com este fator, os indivíduos produtivos não apenas deixam de produzir riquezas mas passam a utilizar recursos para manutenção de sua saúde.

Tabela 01: Limites ABNT para Emissão de Ruídos (em db(A)) (NBR 10.151/2000)

\begin{tabular}{|l|c|c|}
\hline \multicolumn{1}{|c|}{ Tipos de áreas } & Diurno & Noturno \\
\hline Areas de sitios e fazendas & 40 & 35 \\
\hline Area estritamente residencial urbana ou de hospitais ou de escolas & 50 & 45 \\
\hline Área mista, predominantemente residencial & 55 & 50 \\
\hline Área mista, com vocaçåo comercial e administrativa & 60 & 55 \\
\hline Área mista, com vocação recreacional & 65 & 55 \\
\hline Área predominantemente industrial & 70 & 60 \\
\hline
\end{tabular}

Fonte: ABNT (2000). 
Por este efeito perverso e negativo, os autores consideram um duplo impacto negativo, pois não apenas o nível econômico será afetado, mas principalmente a qualidade de vida. Não são descritas somente enfermidades referentes ao aparelho auditivo, mas também ocorrem desdobramentos nos níveis de pressão sanguínea, decorrentes de stress comprometendo assim o bom funcionamento do corpo humano e acarretando no possível aparecimento de outras doenças prejudiciais aos indivíduos.

Lacerda (2005), afirma que um elemento crucial é desconsiderado pela população em geral: o aumento escalar da potência sonora. Enquanto muitos acreditam que a adição de uma unidade $(\mathrm{dB}(\mathrm{A}))$ de pressão representa um acréscimo linear na potência de determinado emissor, esta grandeza é em escalar e aumenta em uma proporção muito maior. O acréscimo desta mesma unidade pode representar um ganho percentual superior a uma unidade, conforme mencionado. Desta forma, em níveis já elevados, o acréscimo de mais unidades é extremamente prejudicial a saúde humana. Por outro lado, adotar medidas que visem diminuir ou mesmo mitigar a disseminação indiscriminada destes ruídos é extremamente benéfico para os seres humanos.

Os níveis elevados de poluição estão concentrados principalmente no primeiro ponto, devido a sua proximidade com zonas de maior circulação de pedestres e veículos. Observam-se fontes pontuais (alguns pontos de comércio com alto-faltantes) e difusas (circulação de automóveis) na emissão de ruídos em altos níveis. Os níveis já altos provocam reações em cascata com a necessidade de emissão em níveis ainda superiores de novos elementos acústicos para a escuta compreensível.

Já no segundo ponto de medição, apesar da declividade pouco acentuada do terreno e a distância mencionada ao início (duas quadras acima do primeiro local), percebe-se uma situação completamente diferente, com a predominância de níveis de pressão sonora próximos aos limites legais, com a emissão pontual de ruídos em níveis elevados (campainhas de entrada de garagens e moradores dos edifícios). Mesmo que um pouco acima do limite estabelecido, a sensação acústica 
é extremamente agradável e não parece causar incômodo aos transeuntes.

Entretanto, no primeiro ponto, mesmo com níveis elevados de pressão sonora, a sensação percebida é de um pequeno desconforto e não algo ensurdecedor. Faz-se necessária a colocação de algumas barreiras acústicas, tal como arborização no canteiro central e calçadas da via, por exemplo, mas aqui também não é insuportável o desconforto percebido. Certamente que esta não é a recomendado para exposição por longos períodos.

Neste ponto, tanto TRB (2010) menciona que a capacidade das vias urbanas inseridas em áreas residenciais de média e alta ocupação (capacidade de adensamento) deve ser acompanhada da instalação de dispositivos que visem minimizar os efeitos do elevado volume de tráfego. Ao citarmos a via onde se encontra o primeiro ponto, principal (e praticamente único) acesso de todos os bairros da Ilha do Governador ao Aeroporto Internacional do Rio de Janeiro, a Base Aérea do Rio de Janeiro e a toda a área continental do município do Rio de Janeiro, FHWA (2011) indica como opção de barreira acústica a densificação arborização na via, que segundo estudos, reduziriam em alguns bons níveis a exposição humana ao nível de ruído gerado.

\section{CONCLUSÕES E ENCERRAMENTO}

Mediante a situação apresentada, percebe-se que nesta zona urbana percebe-se o efeito negativo do crescimento urbano-econômico em parte do declínio da qualidade de vida local. Pimentel-Souza (1992) e Santos (2004) descrevem que a expansão das zonas urbanas deveriam acompanhar um planejamento prévio para que este importante item não seja desassistido no cotidiano urbano. Desta maneira, as cidades cresceriam de forma ordenada, compartilhando e distribuindo mais bônus do que ônus oriundos do crescimento urbano.

Feldman (2005) complementa afirmar que a cidade de São Paulo foi vítima 
do crescimento urbano desordenado, mesmo com contínuos planos de planejamento em execução. Entretanto, conforme mencionado anteriormente por Correa (2007), a expansão paulistana ocorreu no vetor horizontal com a conquista de terrenos elevados nas zonas Norte e Oeste, além dos alagadiços, mananciais e escarpas da Serra do Mar presente nas zonas Sul e Leste, e simultaneamente vertical com o aumento do gabarito das edificações no Centro e bairros de classe média presentes em seu anel periférico imediato.

Santos (2009) afirma que a urbanização brasileira em grande parte não é precedida de planejamento, bem como controle de ocupação e uso do solo. Mesmo quando existem planos, estes são parcialmente implantados (causando distorções na área que sofreu intervenção) ou completamente executados sem o devido acompanhamento posterior. Com isto, os efeitos percebidos no espaço urbano não apenas são difusos mas também causam prejuízos aos habitantes em medida que, quando um determinado problema é resolvido, não se busca solucionar seus desdobramentos.

Entretanto, conforme mencionado, a distância entre os locais e os diferentes tipos de uso do solo alteram consideravelmente os resultados aferidos. Também é necessário mencionar que, na análise acústica não é considerada apenas o valor medido em um determinado momento, mas também o nível de ruído de fundo do local. Certamente que quanto menor for este valor ocorre uma tendência ao resultado observado também ser menor em relação a áreas com ruídos de fundo mais elevados. Este efeito é percebido nestas aferições: enquanto o ruído de fundo em nível alto demanda maior potência acústica para compreensão na área onde este é menor esta necessidade também é proporcionalmente menor.

Retomando a questão acústica, Fernandez (2002) e Möser (2009) afirmam que a construção de barreiras acústicas são uma alternativa para mitigar o problema e auxiliar na contenção da poluição sonora ou mesmo auxiliar parte de sua dissipação. Lacerda (2005) complementa que estas alternativas devem ser sim implantadas e contidas no planejamento urbano das cidades, mas além destas barreiras, alternativas de restrição da circulação de automóveis e a limitação do 
gabarito das edificações (impactando na densidade de ocupação da área) também são alternativas viáveis que devem ser consideradas.

Ferraz (2004) reforça que a implantação de sistemas de transporte público integrados é crucial no desenvolvimento ordenado e sustentável de zonas urbanas. Com o uso intensivo de meios de maior capacidade percebe-se a redução no volume absoluto de automóveis em redução, consequentemente diminuindo a poluição sonora produzida por estes e mitigando a parcela de culpa pertinente ao setor de Transportes. Setti (2011) adenda ao mencionar que a criação de alternativas de circulação, como o uso de binários e o direcionamento balanceado do trânsito pela rede presente também são fatores cruciais, não apenas para melhoria na circulação dos veículos, mas também pela redução da poluição sonora e do ar, contribuindo para o aumento da qualidade de vida local.

\section{REFERÊNCIAS BIBLIOGRÁFICAS}

ABNT. Norma Brasileira (NBR) 10.151: Acústica - Avaliação do Ruído em Áreas Habitadas Visando o Conforto da Comunidade - Procedimento. Rio de Janeiro: Editora ABNT, 2000.

BEZERRA, Carlos Aberto (Org). O Mercosul e as Normas Técnicas. Brasília: Revista do Instituto Brasileiro de Informação, Ciência e Tecnologia (IBICT) (Volume 22 / Número 01), 1993.

CASTRO, Carlos. Medição da Pressão Sonora em Dois Pontos da Ilha do Governador - RJ. Rio de Janeiro: Trabalho submetido a II Conferência Internacional Megaeventos e a Cidade, 2013.

CORREA, Roberto Lobato. Região e Organização Espacial. São Paulo: Ática, 2007.

FHWA (Federal Highway Administration). A Guide to Visual Quality in Noise Barrier Design. Washington D.C (Estados Unidos): The National Library Press, 2011.

FELDMAN, Sarah. Planejamento e Zoneamento: São Paulo de 1947 a 1972. São Paulo, EdUSP, 2005.

FERNANDEZ, João Cândido. O Ruído Ambiental: Seus Efeitos e seu Controle. Bauru: Apostila do Departamento de Engenharia Mecânica da FEB/UNESP, 2002.

FERRAZ, Antônio Clóvis. Transporte Público Urbano. São Carlos: Rima, 2004.

IBGE. Censo Populacional de 2010. Brasília: Editora IBGE, 2010.

IPP. Atlas Sócio-Econômico do Município do Rio de Janeiro. Rio de Janeiro: Imprensa Oficial do Rio de Janeiro, 2013.

LARCERDA, Adriana (Org). Ambiente Urbano e Percepção da Poluição Sonora. Rio de Janeiro: Revista Ambiente \& Sociedade (Volume VIII / Número 02), 2005.

MÖSER, Michael. Engineering Acoustics. Nova York (Estados Unidos): Springer Publishing, 2009. 
PIMENTEL-SOUZA, Fernando. Efeitos da Poluição Sonora na Saúde e no Sono em Geral - Ênfase Urbana. Santa Maria: Revista Brasileira de Acústica e Vibrações (Volume 10), 1992.

SANTOS, Milton. O Espaço Dividido. São Paulo: EdUSP, 2004.

SANTOS, Milton. A Urtbanização Brasileira. São Paulo: EdUSP, 2009.

SETTI, José Reynaldo. Tecnologia dos Transportes. São Carlos: Apostila do Departamento de Transportes (STT) da EESC/USP, 2011.

TRB (Transportation Research Bureau). Highway Capacity Manual 2010. Washington D.C: The National Academy of Sciences Press, 2010. 